\title{
Seynod, Montagny-Les-Lanches
}

A 41, diffuseur de Chaux

\section{Franck Gabayet}

\section{(2) OpenEdition}

Journals

Édition électronique

URL : http://journals.openedition.org/adlfi/1712

ISSN : 2114-0502

Éditeur

Ministère de la culture

Référence électronique

Franck Gabayet, «Seynod, Montagny-Les-Lanches », ADLFI. Archéologie de la France - Informations [En ligne], Rhône-Alpes, mis en ligne le 01 mars 2008, consulté le 19 avril 2019. URL : http:// journals.openedition.org/adlfi/1712

Ce document a été généré automatiquement le 19 avril 2019

(c) Ministère de la Culture et de la Communication, CNRS 


\title{
Seynod, Montagny-Les-Lanches
}

\author{
A 41, diffuseur de Chaux
}

\section{Franck Gabayet}

\section{Identifiant de l'opération archéologique : 9930}

Date de l'opération : 2008 (EX)

1 En préalable à la construction d'un diffuseur autoroutier dans un secteur potentiellement susceptible de receler des vestiges antiques, un diagnostic archéologique a porté sur un lot d'environ 5 hectares, à cheval sur les territoires de l'ancienne commune de Chaux (rattachée à Seynod depuis 1973) et de Montagny-les-Lanches.

2 Selon P. Broise, la plupart des hameaux formant la commune de Seynod ont livré des vestiges antiques, sous la formes tegulae,notamment au hameau de Chaux, voire de substructions (Broise, 1984). L'auteur estime, avec C. Marteau, que la commune était traversée par la voie romaine de Boutae(Annecy) à Aquae(Aix-les-Bains) comme en attestent deux tronçons de chaussée large de $4 \mathrm{~m}$, déterrés en 1893 et 1898 au sud du chef-lieu, ainsi que des toponymes significatifs tels que l'Etraz, la Bunaz et le Treige.

Le diagnostic mené sur l'emprise du futur diffuseur n'aura pas permis de repérer le tracé de la voie d'Aix-les-Bains à Annecy. En revanche, les vestiges d'une occupation de l'âge du Bronze ont pu être identifiés, grâce à la présence d'un niveau de circulation percé de trous de poteaux et de trois grandes fosses, dont la vocation reste à préciser. Le mobilier céramique, sans être abondant, permet de situer l'occupation dans la seconde moitié du Bronze final (Bronze final IIb-IIIa et Illb).

4 Les vestiges de deux fosses, qui ne sont pas sans évoquer les structures de combustion en fosse à pierres chauffées de la même époque ont été ailleurs repérées plusieurs centaines de mètres plus à l'ouest. Les deux fosses sont mal identifiées et livrent pour tout mobilier un fragments de tegula,peu en accord avec la datation attendue.

5 L'époque antique, en l'occurrence un large intervalle de temps compris entre le $\mathrm{I}^{\mathrm{er}} \mathrm{s}$. et le III ${ }^{e}$ s. apr. J.-C., apparaît sous la forme d'une couche formée par une accumulation de 
matériaux probablement des colluvions, qui recèle un mobilier céramique, mais surtout métallique avec en particulier des déchets de forge (fragments de tuyères, scories, battitures, etc.).

6 La question reste posée de savoir si ces vestiges sont effectivement en position secondaire, et sont issus du sommet de la colline voisine où des découvertes anciennes témoignent d'une occupation intense. On pourrait, au contraire, envisager que le bas de la pente a vu la mise en place de structures secondaires, de type artisanal. Dans le cadre stricte du diagnostic, il est délicat de proposer des réponses satisfaisantes.

\section{INDEX}

Thèmes : céramique, forge, fosse, scories, trou de poteau, tuile operation Expertise (EX)

Index chronologique : Bronze récent III, Ier siècle apr. J.-C., IIe siècle apr. J.-C., IIIe siècle apr. J.C.

Index géographique : Rhône-Alpes, Haute-Savoie (74), Seynod

\section{AUTEUR}

FRANCK GABAYET

INRAP 